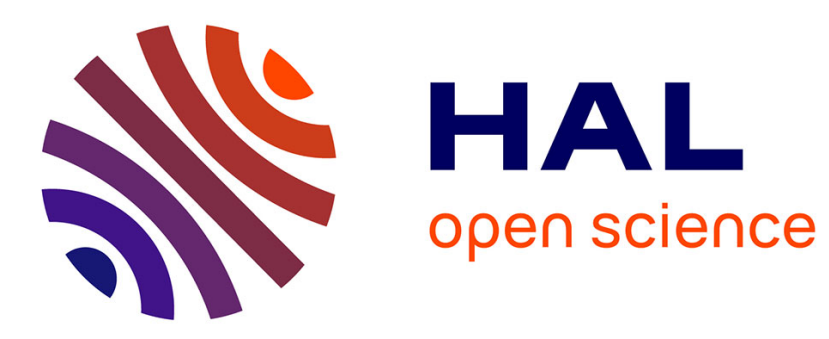

\title{
Seismic evidence of fluid migration in northeastern Japan after the 2011 Tohoku-Oki earthquake
}

Qingyu Wang, Michel Campillo, Florent Brenguier, Albanne Lecointre, Tetsuya Takeda, Keisuke Yoshida

\section{- To cite this version:}

Qingyu Wang, Michel Campillo, Florent Brenguier, Albanne Lecointre, Tetsuya Takeda, et al.. Seismic evidence of fluid migration in northeastern Japan after the 2011 Tohoku-Oki earthquake. Earth and Planetary Science Letters, 2021, 563, pp.116894. 10.1016/j.epsl.2021.116894 . hal-03180473

\section{HAL Id: hal-03180473 https://hal.univ-grenoble-alpes.fr/hal-03180473}

Submitted on 25 Mar 2021

HAL is a multi-disciplinary open access archive for the deposit and dissemination of scientific research documents, whether they are published or not. The documents may come from teaching and research institutions in France or abroad, or from public or private research centers.
L'archive ouverte pluridisciplinaire HAL, est destinée au dépôt et à la diffusion de documents scientifiques de niveau recherche, publiés ou non, émanant des établissements d'enseignement et de recherche français ou étrangers, des laboratoires publics ou privés. 
1 Seismic evidence of fluid migration in northeastern Japan after the 2011 Tohoku-Oki

2 earthquake

3

4 Qing-Yu Wang ${ }^{1,2}$, Michel Campillo ${ }^{1}$, Florent Brenguier ${ }^{1}$, Albanne Lecointre ${ }^{1}$, Tetsuya

5 Takeda $^{2}$, Keisuke Yoshida ${ }^{3}$

6 1. Department of Earth, Atmospheric and Planetary Sciences, Massachusetts Institute of 7 Technology, Cambridge, USA.

8 2. Université Grenoble Alpes, CNRS, ISTerre, Grenoble, France

9 3. National Research Institute for Earth Science and Disaster Resilience, Japan

10 4. Department of Geophysics, Graduate School of Science, Tohoku University, Japan

11

12 *Corresponding author : Qing-Yu Wang

13 Address : ISTerre, 1381 Rue de la Piscine, Saint Martin d'Hères, 38400, France

14 Email : qingyuwa@mit.edu

15 Tel : +33(0)6 01122194 


\section{Abstract}

17

18 We use ambient-noise-based seismic monitoring to detect an anomalous seismic velocity 19 decrease $(\sim 0.01 \%)$ widely distributed in Honshu that arose about 1 year after the $2011 \mathrm{M}_{\mathrm{w}}$ 209.0 Tohoku-Oki earthquake. The anomaly is located along the central quaternary volcanic 21 axis, and it suggests that the changes are related to volcanic processes. After correction for possible external environmental forcing-related velocity changes, the anomaly in the seismic velocity remains, which implies that it is associated with some internal physical process. We show a general strong positive correlation between the seismic velocity changes and the intensity of ground motion derived from the daily cumulative seismic moment. However, the lack of correlation during the anomaly itself reveals that this reduction is not directly caused

27 by earthquake shaking. Tiltmeter low-pass observations show temporal variations that are correlated with the velocity changes. These observations strengthen the hypothesis of actual physical deformation. A previously reported decrease in fault strength $(\sim 10 \%)$ for the same period as the velocity anomaly further supports a physical property change in the upper crust. We also note a simultaneous increase in activity of low-frequency events in the volcanic area, which suggests an increase in pore pressure in the upper crust. We propose that the observed anomalous seismic velocity decrease in early 2012 is due to an increase in pore pressure induced by an upward fluid migration, which at the same time triggered the increase in fluiddriven swarm seismicity and low-frequency events. We recall the depth-dependent seismic velocity changes in Honshu and derive an average diffusion of $1 \mathrm{~m}^{2} / \mathrm{s}$ over around 11 months after the Tohoku-Oki earthquake.

\section{Keywords:}


40 Seismic velocity drop anomaly; Fluid migration; Low frequency earthquakes; Tiltmeter 41 observation; Pore pressure; Fault strength.

42 


\section{Introduction}

44

Ambient noise monitoring allows changes in seismic wave velocities related to large earthquakes to be followed. The main observation is the rapid coseismic velocity drop at shallow depths under the impact of strong ground motion caused by earthquakes, such as: the $2004 \mathrm{M}_{\mathrm{w}}$ 6.0 Parkfield (Brenguier et al. 2008) and $2008 \mathrm{M}_{\mathrm{w}} 7.9$ Wenchuan (Chen et al., 2010; Froment et al., 2013) earthquakes; the $2009 \mathrm{M}_{\mathrm{w}} 6.3$ L'Aquila earthquake (Poli et al., 2020); the $2011 \mathrm{M}_{\mathrm{w}}$ 9.0 Tohoku-Oki earthquake (Brenguier et al., 2014; Sawazaki et al., 2015; Wang et al., 2019); and the $2014 \mathrm{M}_{\mathrm{w}}$ 6.0 South Napa earthquake (Taira et al., 2015). Shallow-depth changes are also due to seasonal velocity changes caused by environmental forces (Hobiger et al., 2012; Wang et al., 2017; Poli et al., 2020). Deeper static strain (Wang et al., 2019) and strong aftershocks (Sawazaki et al., 2015) can also cause distinctive changes in seismic wave velocities, as seen for the 2011 Tohoku-Oki earthquake.

In this study, we use data from the short-period seismic network Hi-net (Okada et al., 2004; Obara et al., 2005) that provides even cover of the island of Honshu. We focus on the response of the shallow crust in the frequency range from $0.15 \mathrm{~Hz}$ to $0.90 \mathrm{~Hz}$, which is basically down to a depth of about $5 \mathrm{~km}$, according to the surface wave sensitivities of the ambient seismic noise. A large coseismic drop of velocity occurred coincident with the Tohoku-Oki earthquake of March 11, 2011. After a short relaxation time, the velocity reached a minimum with the significant aftershock of $M_{w} 7.2$ on April 7, 2011, near the east coast of Honshu. Then the velocity started to gradually increase following a roughly logarithmic recovery, in a way similar to that observed after several events with periods $<10 \mathrm{~s}$ (Brenguier et al., 2008; Wegler et al., 2009; Hobiger et al., 2012; Taira et al., 2015). In the case of the Tohoku-Oki earthquake, about 11 months after the earthquake, there was a 
secondary episode of decreased velocity that occurred for a large number of the stations in Honshu. We outline this secondary episode of decrease in velocity as the seismic evidence of fluid migration after the Tohoku-Oki earthquake.

The velocity changes averaged over northern Honshu show a late anomalous seismic velocity drop. The spatial distribution of the amplitudes of these velocity drops correlates with the central volcanic axis, where is in agreement with the volcanic subsidence of $5-15 \mathrm{~cm}$ just after the Tohoku-Oki earthquake reported by Takada \& Fukushima (2013). They discussed the possible origins with two major hypothesis of hot and weak material, water release. In this paper. We first correct the possible environmental effects with different experiments and confirm the existence of this velocity anomaly in this special location. Seismic intensity envelops based on the seismicity can perfectly explain the global changes in seismic velocity even some quick and small velocity variations, especially for the time period before the Tohoku-Oki earthquake. Nevertheless, there is a lack of evidence to correlate this anomaly in 2012 to the intensity envelop. By comparing borehole tiltmeter recordings from the same site, we identify a similar anomaly for the tiltmeter low-pass time series, with ground tilt of several microradians. Other observations, such as the synchronous increased rate of lowfrequency earthquakes (LFEs) and the simultaneous decrease in fault strength (Yoshida et al., 2016) around the volcanic area, contribute further arguments on tracing the common physical origins. With comprehensive observations and discussions, we speculate that these regional velocity decreases are likely to be directly related to the activities of underground fluids. The upward fluid migration through the crust led to the increase of the pore pressure and further produced this seismic velocity decrease anomaly. Based on all the depth-dependent observations (Want et al., 2019), we derive an average diffusion through the crust of $\sim 1 \mathrm{~m}^{2} / \mathrm{s}$ over around 11 months after the mainshock in Honshu. 


\section{Data and observations}

95

We use the data for the continuous daily seismic velocity changes measured using noise-

97 based monitoring in the frequency range of $0.15 \mathrm{~Hz}$ to $0.90 \mathrm{~Hz}$ (Wang et al., 2017), and focus on an interpretation of the seismic decrease anomaly observed in early 2012 in Honshu. Figure 1a shows the $236 \mathrm{Hi}$-net stations that provide the data used in this study. We get the seismic velocity changes at each station using the doublet and inversion method (Brenguier et al., 2014). More details of the data processing procedures and methods applied are given in

102 Wang et al. (2017).

When only the Rayleigh wave sensitivity kernels are considered, the velocity measurements in the studied frequency band mainly characterize the changes in the physical properties within the $5 \mathrm{~km}$ of the upper crust (Obermann et al., 2018; Wang et al., 2019). Using the time series of the velocity changes (Figure 1b) averaged over all of stations in Figure 1a, it is possible to identify some rapid velocity drops that are coincident with some large earthquakes. After checking all the earthquakes with magnitude larger than six, we are able to easily identify velocity decreases related to six earthquakes larger than magnitude around seven.

111 The dates of earthquakes are indicated by the red vertical dashed lines in Figure $1 \mathrm{~b}$. The six 112 large earthquakes from the JMA catalog are separately: $\mathrm{M}_{\mathrm{w}} 7.0$ on May 8, 2008; $\mathrm{M}_{\mathrm{w}} 7.2$ on

113 June 14, 2008; $\mathrm{M}_{\mathrm{w}} 6.9$ on July 19, 2008; $\mathrm{M}_{\mathrm{w}} 9.0$ on March 11, 2011; $\mathrm{M}_{\mathrm{w}} 7.2$ on April 7, 2011; 114 and $M_{w} 7.2$ on December 7, 2012. Among these earthquakes, the $M_{w} 9.0$ Tohoku-Oki 115 earthquake on March 11, 2011 produced the largest velocity drop. After the Tohoku-Oki 116 earthquake, the velocity then increased due a relaxation process that has been reported 117 previously in a number of studies (Brenguier et al., 2014; Hobiger et al., 2012; Wang et al., 
118 2019). The minimum velocity reached is actually coincident with its significant aftershock of $119 \quad \mathrm{M}_{\mathrm{w}}$ 7.3 on April 7, 2011.

120 
(a)

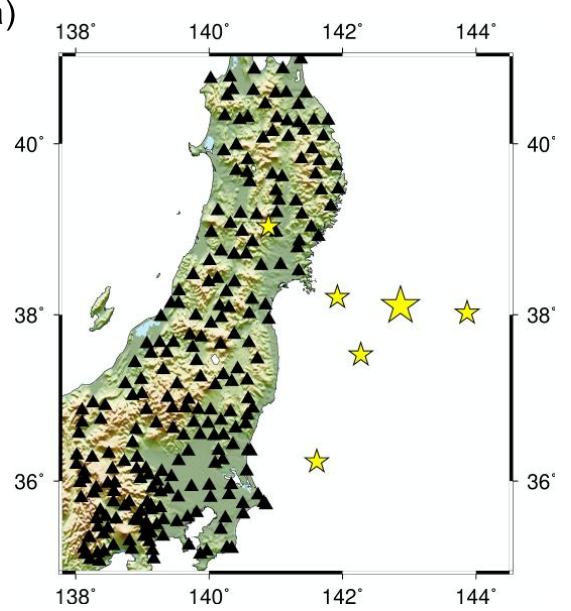

(c)

121

122

123

124

125

126

127

128

129

130

131

132

133

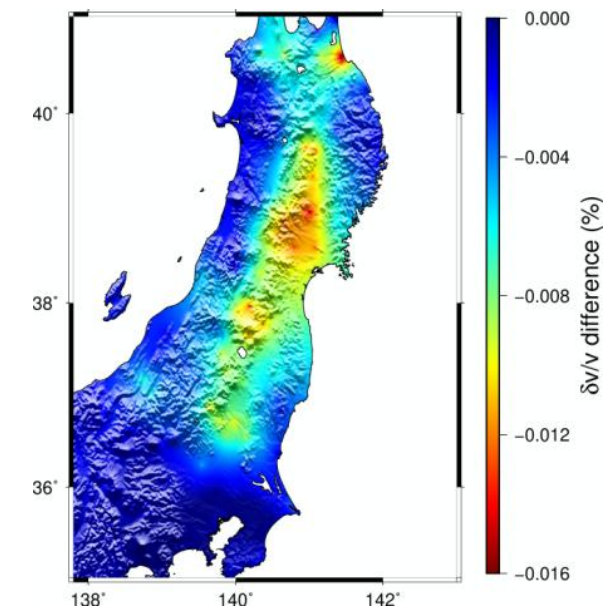
(c) and after removal of the environmental effects (d). (b)

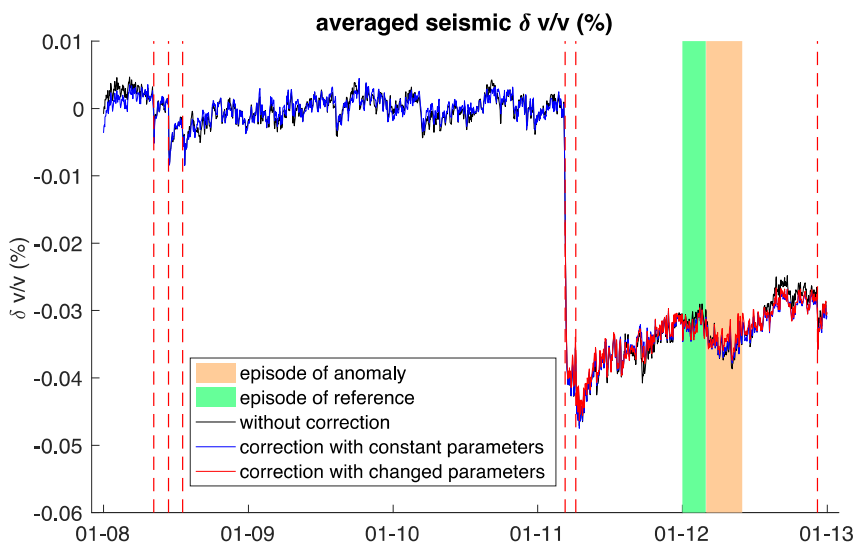

(d)

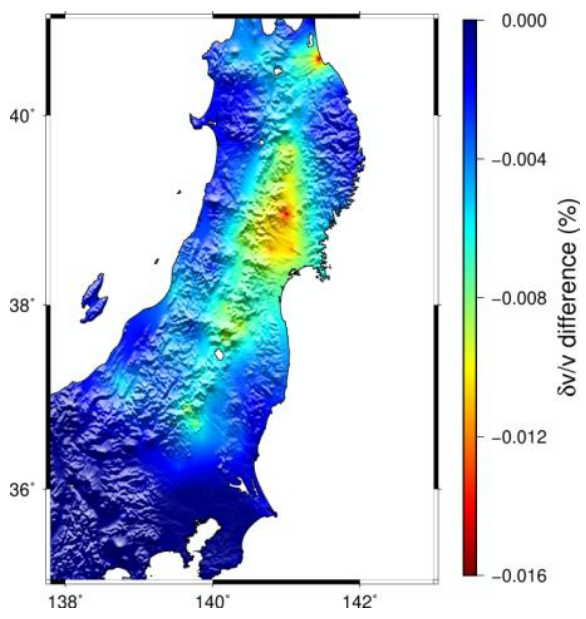

Figure 1. (a) Map of the study area. Black triangles, the $236 \mathrm{Hi}$-net stations for the data used in this study; yellow stars, epicenters of the earthquakes considered, are separately the $\mathrm{M}_{\mathrm{w}}$ 7.0, $08-\mathrm{May}-2008\left(36.24^{\circ} \mathrm{N}\right.$ $\left.141.61^{\circ} \mathrm{E}\right)$, the $\mathrm{M}_{\mathrm{w}} 7.2,14-\mathrm{Jun}-2008\left(39.04^{\circ} \mathrm{N} 140.89^{\circ} \mathrm{E}\right)$, the $\mathrm{M}_{\mathrm{w}} 6.9,19-\mathrm{Jul}-2008\left(37.52^{\circ} \mathrm{N} 142.27^{\circ} \mathrm{E}\right)$, the $\mathrm{M}_{\mathrm{w}}$ 9.0, 11-Mar-2011 $\left(38.11^{\circ} \mathrm{N} 142.87^{\circ} \mathrm{E}\right)$, the $\mathrm{M}_{\mathrm{w}}$ 7.2, 07-Apr-2011 (38.21 $\left.{ }^{\circ} \mathrm{N} 141.92^{\circ} \mathrm{E}\right)$, and the $\mathrm{M}_{\mathrm{w}} 7.207-\mathrm{Dec}-$ $2012\left(38.02^{\circ} \mathrm{N} 143.87^{\circ} \mathrm{E}\right)$. (b) Time series of averaged seismic velocity changes. Black curve represents the time series for the seismic velocity changes averaged over all of the $236 \mathrm{Hi}$-net stations in (a). Blue curve and red curve are corrected velocity changes with constant parameters and changed parameters, respectively. Red vertical dashed lines, dates of the earthquakes (a; yellow stars); green shaded time period, reference episode before the anomaly; orange shaded time period, anomaly episode. (c, d) Maps showing the differences in the changes in seismic velocities between the anomaly episode and the reference episode in (b), without correction 
134 Aside from the earthquake-related velocity changes, there is an anomalous seismic velocity 135 decrease of $\sim 0.01 \%$ in early 2012 (highlighted by the orange band, Figure $1 \mathrm{~b}$ ). The amplitude

136 of this anomaly is comparable to the abrupt decreases associated with the indicated

137 magnitude 7.0 earthquakes (e.g., Iwate-Miyagi Nairiku inland earthquake on June 14, 2008).

138 In Figure 1b, the black time series shows the raw monitoring result without any correction for

139 the external environmental effects. The differences between the variations of the seismic

140 velocities averaged for the two time periods indicated by the green shaded band (from

141 January 1, 2012 to February 29, 2012) and the orange band (from March 1, 2012 to May 31,

142 2012) in Figure 1b are then calculated. The map of this difference is shown in Figure 1c, and

143 this illustrates the correspondence between the velocity drop and the central volcanic zone.

144 Therefore, we consider this velocity anomaly to be located in the upper crust of the volcanic 145 area, which is believed to have high susceptibility of velocity changes to stress perturbations

146 (Brenguier et al., 2014). This specific distribution is a good indication that the drop is not an 147 artifact of the measurements, as such an effect of a change in the nature of the noise would 148 not be expected to correlate with the geological structure.

150 The overall changes (Figure 1b, black curve) in the study area are stable in time, other than 151 the occurrence of a significant earthquake or this anomaly in early 2012 . This velocity change 152 anomaly does not show the characteristics of seasonal effects. Wang et al. (2017) show that 153 seasonal variations on the east side of Honshu Island are weak. Nevertheless, it is recognized 154 that seismic wave velocities can be strongly affected by many surrounding environmental 155 perturbations, e.g., groundwater level changes and rainfall can decrease seismic velocities by $1560.01 \%$ to $0.1 \%$ through increased pore pressure (Sens-Schönfelder \& Wegler, 2006; Meier et 157 al., 2010; Hillers et al., 2014; Wang et al., 2017). Also, some direct loading associated with 158 snowfall, precipitation, and sea-surface height changes can affect the seismic wave velocities 
159 (Wang et al., 2017; Donaldson et al., 2019). Further, in the shallow layer, thermoelastic stress 160 and atmospheric pressure can modulate the seismic wave velocities on an annual cycle

161 (Meier et al., 2010; Richter et al., 2014; Hillers et al., 2015). Therefore, we first investigate 162 whether the environmental factors represent the origin of this anomaly. Wang et al. (2017) 163 propose a scheme of correction for these effects based on the actual observations of 164 precipitation, snow load, and sea-surface height variations. The correction is empirically 165 parameterized from the observations between 2009 and 2010, a period during which no major earthquakes occurred in this region.

168 The first operation here is to apply the linear model of Wang et al. (2017) to correct the 169 possible changes from combined effects of hydro-meteorological factors. The parameters of 170 the correction at each station are established using the period from 2009 to 2010, when no 171 known major seismic events occurred. The extension of this correction to the period of 2011 172 to 2012 is carried out under the assumption that the changes in the seismic velocity due to the 173 external forcings after the Tohoku-Oki earthquake are identical to those before it. Beyond 174 this constant parameter correction, a correction is also performed with the new model 175 parameters obtained from the period following the Tohoku-Oki earthquake, which covers the 176 period of the anomaly. The assumption behind this second correction is that the sensitivities 177 to the hydro-meteorological factors change due to the crustal deformation induced by the 178 earthquake. Thus, the contributions of the hydro-meteorological forcings to the seismic 179 velocities might be different from those before the earthquake. The postseismic environmental-effect correction is applied after the time series is detrended to remove the effects of the coseismic and postseismic long-term tendencies. The parameters for this correction are determined to minimize the velocity fluctuations, and are based on the actual

183 time series of local observations for precipitation, snow, and sea-surface height. The time 
interval used covers the period of the anomaly. Hence, this correction optimizes the removal of the anomaly.

187 We show in Appendix (Figure A1) the corrected seismic velocity changes from each station

188 by gray curves. In global, this anomaly is evident from abundant stations, especially stations with high coseismic velocity drops. Figure $1 \mathrm{~b}$ shows the averaged time series of seismic velocity changes over the $236 \mathrm{Hi}$-net stations without and with the external effect corrections. It can be seen from that without or with the model corrections, the influence on the averaged anomalous velocity decreases is subtle. The secondary velocity drop persists after both of these environmental effect corrections. The amplitudes of the anomaly after the corrections are still comparable to the changes due to the inland Iwate-Miyagi Nairiku earthquake in 2008. The preserved anomaly confirms the interpretation of the second drop as the evidence of changes in the physical properties of the medium that are not governed by environmental factors. In the following, we consider the seismic velocity time series that is corrected with the model which is parameterized based on the years preceding the anomaly (Wang et al., 2017) as corrected velocity changes, and with the local meteorological and oceanographic observations as input.

Figure 1c, d show the maps of the differences of the averaged seismic velocities during the two episodes indicated in Figure $1 \mathrm{~b}$ (green and orange shading), without any corrections

204 (Figure 1c) and after the correction with the constant parameters (Figure 1d). From these maps of the spatial distributions of the velocity differences, it can be seen that before the correction, the anomaly was mainly along the central volcanic axis (Figure 1c). When the correction based on the data before the Tohoku-Oki earthquake is applied, the anomaly is still extensive across the set of stations, and the overall feature is preserved (Figure 1d). The 
distribution characteristics confirm that this velocity reduction occurs in the volcanic area and its vicinity. The particularity of the geographical location of the volcanos and the surrounding

211 area is an essential feature of this velocity anomaly. After discarding the external forcings as

212 the possible source of these observations, the deep origins of this secondary velocity drop

213 anomaly of $\sim 0.01 \%$ are investigated. To clarify this question, we discuss the possible causes

214 of the second drop in the light of different independent observations from occurrence of regular seismicity and LFEs in the Honshu island, and from tilt recordings and fault strength in small scale.

\section{Nonlinear responses to earthquake ground motion}

Strong ground motions induced by earthquake shaking affect shallow seismic velocities

Wegler, 2011; Brenguier et al., 2014; Sawazaki et al., 2015; Wang et al., 2019). We take advantage of the JMA catalog within latitudes $34^{\circ} \mathrm{N}-42^{\circ} \mathrm{N}$ and longitudes $138^{\circ} \mathrm{E}-143^{\circ} \mathrm{E}$, to convert the seismic magnitudes into the corresponding seismic intensities of shaking and to compare their relationship with the seismic velocity changes. As Katsumata (1996) and Uchide \& Imanishi (2018) have reported, there are some systematic differences in the magnitude scales between the $\mathrm{M}_{\mathrm{JMA}}$ and the conventional moment magnitude $\mathrm{M}_{\mathrm{w}}$. Therefore, we first transformed the $\mathrm{M}_{\mathrm{JMA}}$ into $\mathrm{M}_{\mathrm{w}}$ for $0.5 \leq \mathrm{M}_{\mathrm{JMA}} \leq 7.0$ using Equation (1), as proposed by Uchide \& Imanishi (2018):

230

231

$$
M_{w}=a M_{J M A}^{2}+b M_{J M A}+c
$$


where parameters $\mathrm{a}, \mathrm{b}$, and $\mathrm{c}$ are $0.053,0.33$, and 1.68 , respectively. We then evaluated the moment according to Equation (2), from Hanks \& Kanamori (1979):

235

236

$$
M_{0}=10^{\left(M_{w} * 1.5+9.05\right)}
$$

Then we compare the corrected velocity time series with the ground motion deduced from the moments. For each seismic moment observation, the intensity of the shaking is evaluated from the approximate ground velocity. We assume the classical scaling of $\mathrm{M}_{0}$ with the cube

241 of the duration and the constant stress drop. Therefore, we propose Equation (3) to calculate 242 the normalized cumulative intensity (I), considering both the geometric decay and the nonelastic attenuation from the hypocenters to the seismic stations.

$$
(I)_{i}=\left\{\sum_{n=1}^{N_{i}}\left(M_{0_{n}}{ }^{1 / 3} * \frac{1}{r_{n}^{j}}\right)\right\} e^{-t_{n} / t^{*}}
$$

247 where $M_{0 n}$ is the seismic moment, $r_{n}$ is the distance to the hypocenter, $t_{n}$ is the travel-time 248 from source to station with a velocity of $3 \mathrm{~km} / \mathrm{s}$ for every event $\mathrm{n}, \mathrm{t}^{*}$ is to account for the 249 nonelastic attenuation, $\mathrm{i}$ is the $\mathrm{i}^{\text {th }}$ day in the time series, $\mathrm{N}_{\mathrm{i}}$ is the total number of events for 250 day $\mathrm{I}$, and $\mathrm{j}$ is the exponent of distance in the geometric spreading factor. In this study, we set $251 \mathrm{j}$ as 1.0 , on the assumption of body waves and $\mathrm{t}^{*}$ as $50 \mathrm{~s}$ for an empirical value. Note that in a 252 far-field approximation for shear waves, the ground velocity is proportional to the dynamic 253 stress. 
(a)

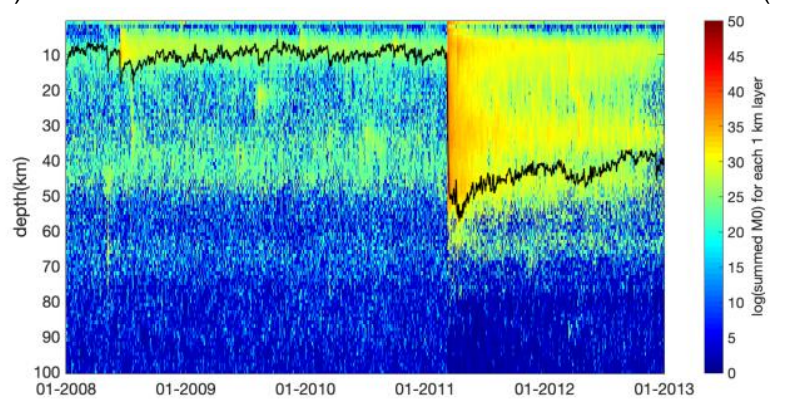

(c)

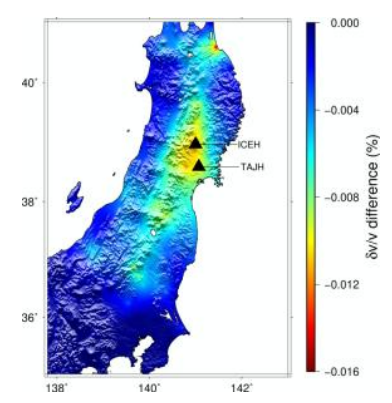

(d) (b)
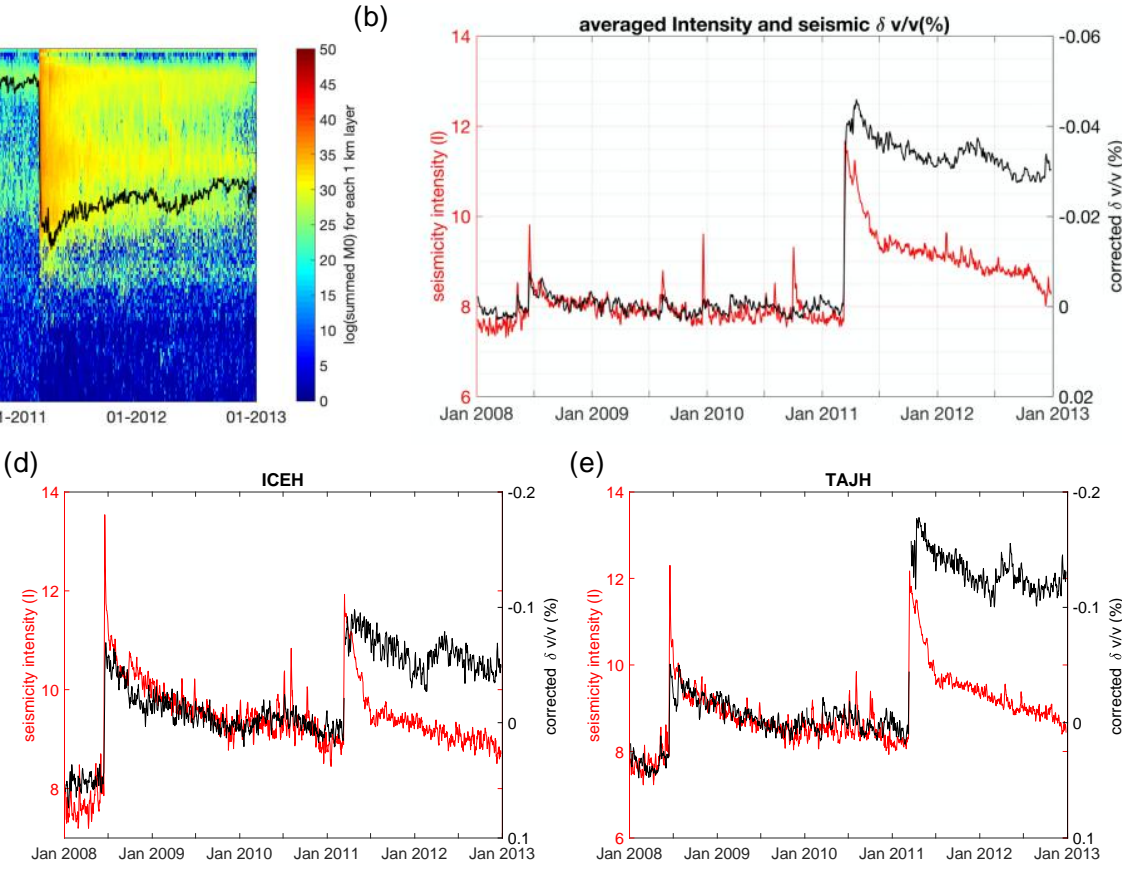

(e)

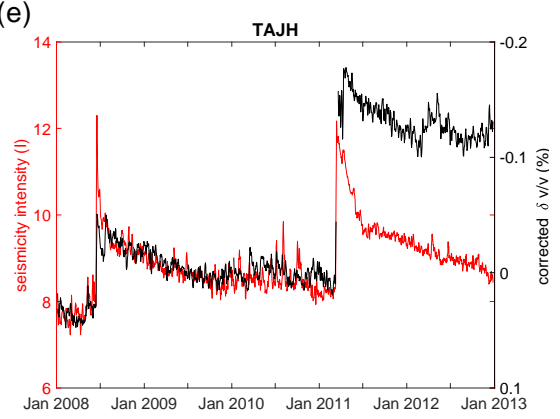

Figure 2. (a) Comparison of $\mathrm{M}_{0}$ within latitudes $34^{\circ} \mathrm{N}-42^{\circ} \mathrm{N}$ and longitudes $138^{\circ} \mathrm{E}-143^{\circ} \mathrm{E}$ and the seismic velocity changes. $\mathrm{M}_{0}$ is normally summed within each 1-km layer, and changes with time at different depths, down to $100 \mathrm{~km}$. For these data, the two-dimensional adaptive noise-removal Wiener filter (Matlab built-in Wiener2) was applied, with the parameter as 5 in both dimensions. Black curve, normally averaged corrected seismic velocity changes over all of the 236 Hi-net stations. (b) Comparison of the daily time series of the averaged-corrected seismic velocities with the daily time series of the averaged seismic intensity calculated with the seismic events without depth restrictions and $t^{*}$ of $50 \mathrm{~s}$. (c) Map of the secondary drop anomaly and locations of stations ICEH and TAJH. (d, e) Comparisons between the time series of the seismic intensity $(I)$ and the seismic velocity changes at stations ICEH (d) and TAJH (e). To both of these time series we applied a moving-average filter with a window size of 4 days.

Here, we first calculate the summed seismic moments within each kilometer of depth for each day. Figure $2 \mathrm{a}$ shows that the seismic events mainly occur within the first $50 \mathrm{~km}$ in depth, and before the Tohoku-Oki earthquake, they show two concentrations of activity at depths of around $10 \mathrm{~km}$ and $40 \mathrm{~km}$. Within the first 2 years from the mainshock, this deepens to $70 \mathrm{~km}$, with a different depth distribution. To visually understand the relationship between the changes in the seismic velocity and the changes in the seismic intensity, $I$, with time and 
depth, the spatially averaged-corrected seismic velocity changes are plotted on the image of the seismic moment in Figure 2a. Positive global correlation between these two observations is seen before the mainshock. One month after the main shock, there is also a strong correlation between intensity from large aftershocks and seismic velocity, leading to the

277 lowest seismic velocity reached. Nevertheless, when the early 2012 anomaly appears, there is no apparent enhanced seismicity.

279

Figure $2 \mathrm{~b}$ compares the averaged seismic velocity changes for the whole network with the averaged intensities of the ground motion calculated from every station in Figure 2a. The velocity time series are corrected for environmental effects. For visual convenience, the direction of the velocity changes has been reversed here. There is correlation between the changes in the seismic velocity and the seismic intensity, which is particularly striking before and just after the Tohoku-Oki earthquake. Dynamic stress from earthquakes shaking appears to be the main control of rapid velocity during this period.

After the main shock, there is a decrease in the daily ground motion intensity that is related to the aftershock decay. There is also a corresponding general increasing trend in the velocity, although the correlation between the velocity and the earthquake motion intensity is weak, and there is no evidence of a correlation with the early 2012 delayed drop in the velocity; this suggests that the anomalous velocity drop is not related to the seismic ground motion. Here, we just use the averaged velocity and the ground motion evaluated at a single point, while local events might strongly control the ground motion for each station. We also present the same comparison for specific sites of stations ICEH and TAJH, where the delayed velocity drops have large amplitudes. The ground motion intensity is computed specifically for each of these locations. Figure $2 \mathrm{~d}$ and e show the comparisons of the velocity changes and the 
seismic intensities at the ICEH and TAJH stations after smoothing with a 4-day moving time window. Correlations of the velocity drops with the earthquake activity can be seen before the main event. Even the fluctuations with characteristic times of several months correlate well with the seismic motion. However, for the anomalous velocity drops in 2012 , there is no correspondence between the time evolution of the intensity of ground motion and that of the velocity. Notably, in Figure $2 \mathrm{~d}$, there is also a correlation between the seismic velocity decrease and the slightly increased seismic intensity envelop in around July 2010, which is mainly controlled by the local earthquake events near station ICEH. We can see that this correlation has tightened and disappeared at the end of 2010. Nevertheless, this local feature is not dominant in the averaged comparison in Figure $2 \mathrm{~b}$. For these different single stations and the averaged data, it appears that there are other processes at work in addition to the velocity relaxation and seismicity, which have to be invoked to explain the secondary drop that occurs in early 2012.

\section{Comparisons with low-frequency earthquakes}

314 As the process responsible for the secondary velocity drop is located along the volcanic chain, we check the small seismic activity associated with volcanic activity, in the form of (LFEs). The origins of volcanic LFEs are interpreted in relation to the magma activities (Aki et al.,

317 1977; Chouet et al., 1987; Hasegawa \& Yamamoto, 1994; Nakamichi et al., 2003, 2004) or to

318 both migration of crustal fluids and local magma that ascends in southwest Japan beneath the active arc volcanoes (Yu et al., 2018). Furthermore, Aso at al. (2013) report that LFEs beneath Osaka Bay which is out of the volcanic areas are due to fluid upwelling from the mantle. For more general perspectives, LFEs are related to the pressure changes generated by

322 fluid-flow transients (Katsumata \& Kamaya, 2003; Shapiro et al., 2018). We use the JMA 
$324 \mathrm{~km}$. We sum the daily number of LFEs for a 30-day window within the study area. The 325 monthly activities of the LFEs are presented in Figure 3a.

(a)

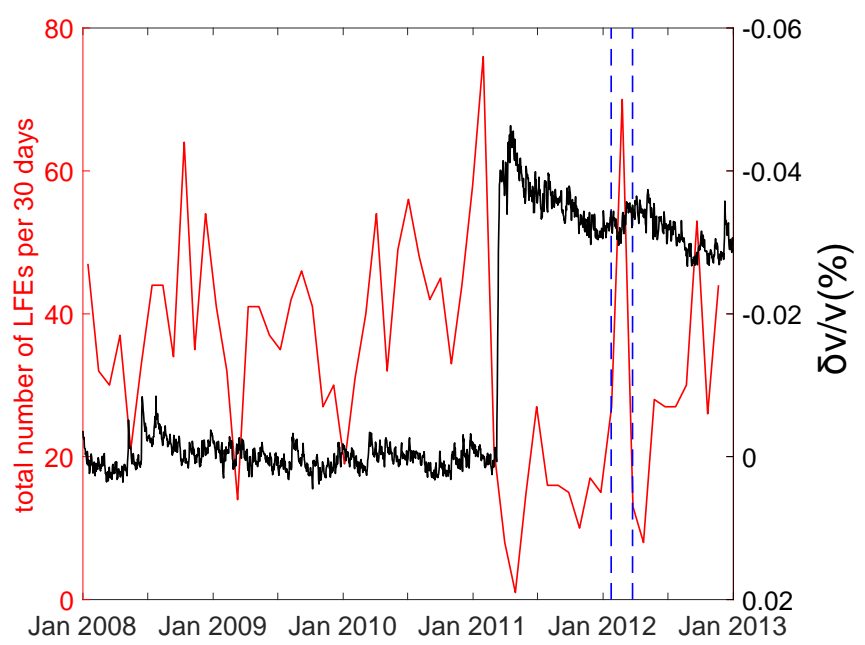

(b)

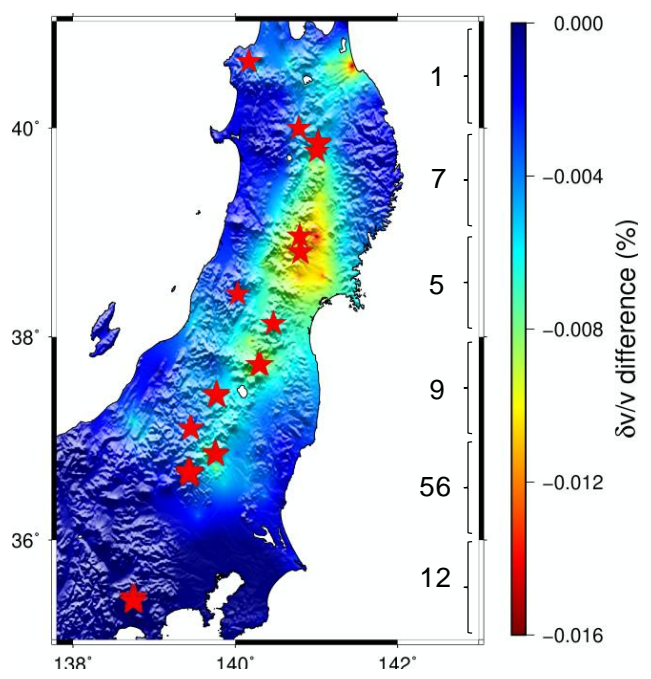

326

327

328

329

330

331

332

333

334

335

Figure 3. (a) Total number of low-frequency earthquakes (LFEs) over each 30-day window, and the averaged seismic velocity changes over the 236 stations in Honshu. (b) Map of the secondary velocity drop and the locations of the epicenters of all the LFEs in the time period between the two vertical blue dashed lines in (a) (January 24, 2012 to March 24, 2012; determined by the times of the peaks). The numbers on the right are summed numbers of LFEs per degree of latitude.

From Figure 3a, the overall number of LFEs appears to drop after the Tohoku-Oki earthquake (Tokuda \& Shimada, 2019), which possibly indicates a change in the physical state of the crust. This might be related to the significant extension of continental crust by the anelastic deformation produced by the event (Tsuji et al., 2013). On the other hand, it needs to be carefully considered whether the intense aftershock activity might affect the detection level. Figure $3 \mathrm{a}$ (black) also shows the seismic velocity changes averaged over all of the $236 \mathrm{Hi}$-net stations. During the period when the seismic wave velocity starts to decrease in early 2012 , the number of LFEs rapidly increases. The decrease in the velocity and the enhanced LFEs 
activity are simultaneous. These observations support the hypothesis that our observations of the seismic velocity are related to fluid transfer in the upper part of the crust.

344 Figure $3 \mathrm{~b}$ shows the epicenters of all of the LFEs in Figure 3a from January 24, 2012 to 345 March 24, 2012 (indicated by the two blue dashed lines). This is the period covering both the 346 sudden increase in LFEs and the decay of the seismic velocity. A large number of the LFEs 347 during this period occur at very close locations and the epicenters are superimposed on the map. We show the counted numbers of LFEs per latitude on the side of Figure $3 b$. A big part of LFEs locates in the area within $36^{\circ} \mathrm{N}$ and $37^{\circ} \mathrm{N}$, and others are mainly along the central volcanic chain, which coincides with the area where the major seismic velocity decrease anomaly occurred in early 2012. Despite the concentration of LFEs in the southern part of the velocity anomaly, these two global spatial distributions are not limited to a small area but cover the wide region of the volcanic chain of Honshu Island. The agreement in both space and time provides further support for our interpretation that this decrease in seismic wave velocity is closely related to deep fluid movement. However, as of the manually-picked catalog of LFEs, the actual number could be underestimated. It should be noted that the depth distribution of LFEs is likely deeper than the layer probed by the waves used in our velocity measurements and is not directly linked to the depth of changes in velocity. Nevertheless, we suggest that further careful cross-investigation on the correlation of LFEs and changes in seismic velocity is important to disclose the stress state of the crust.

\section{Tiltmeter recordings}

364 The Hi-net tiltmeters located in the same boreholes as those for the short period seismic data 365 are used to directly compare the relationship between the seismic velocity changes and the 
ground tilt. Tiltmeters are sensitive to variations of fluid contents or fluid pressures due to

367 different processes, such as groundwater level changes due to precipitation (Sato et al., 1980)

368 and volcanic fluid motion (Ueda et al., 2005). Tiltmeter recordings should give more precise

369 information on local subtle deformation than GPS displacement (e.g., Dzurisin, 2003). We

370 took advantage of these co-sited tiltmeters to see how the ground tilt varies during the

371 velocity anomaly period.

372

(a)

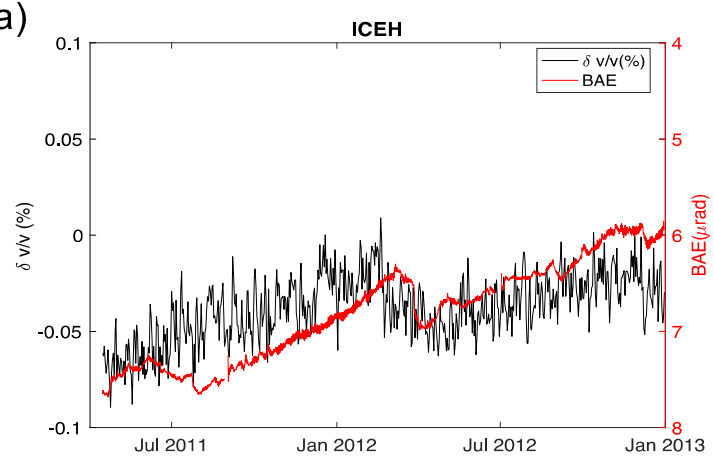

(c)

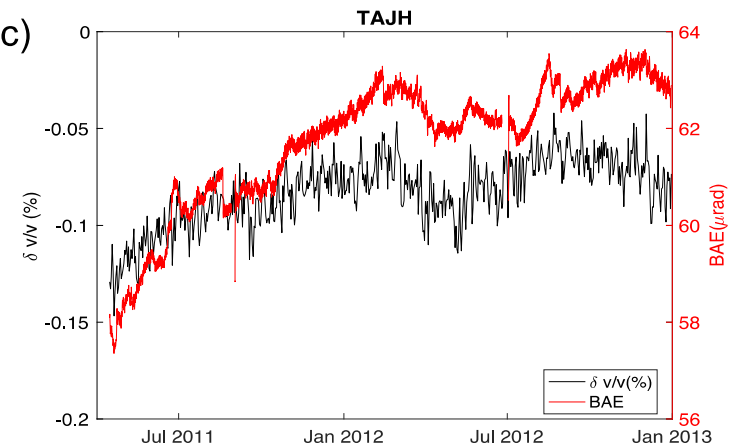

(b)

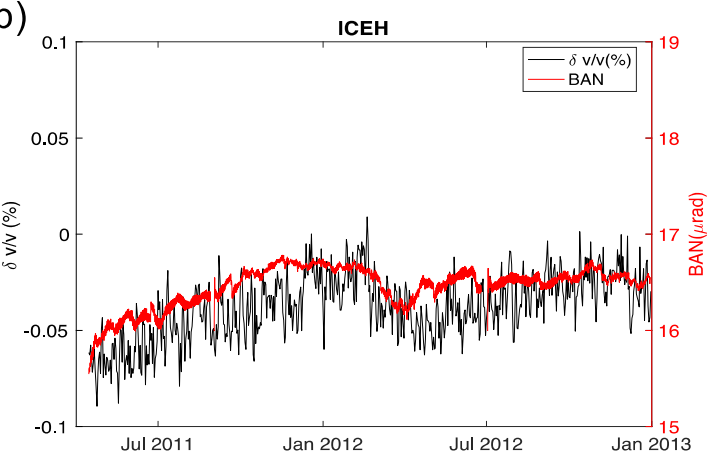

(d)

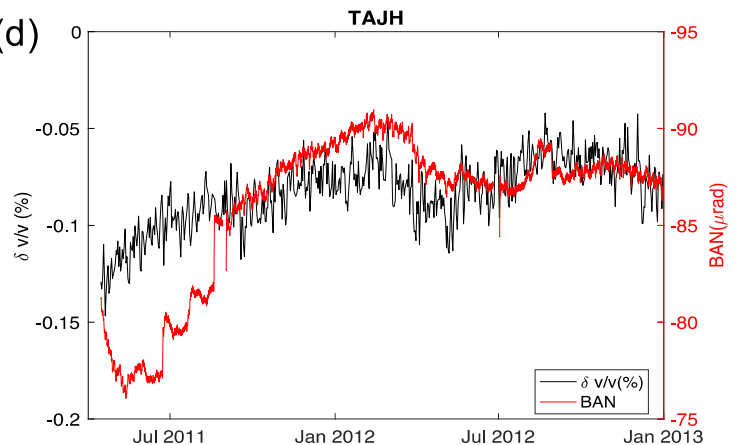

373

Figure 4. Comparisons between the seismic velocity changes and the ground tilt at Hi-net stations ICEH (a, b) and TAJH (c, d) for the two horizontal components. Both time series are positively correlated, except for (a) and (d), where the tilt is plotted upside-down to illustrate the similar anomaly. BAN and BAE are the two horizontal components in directions of N-S and E-W, respectively.

379 The raw daily data is first down sampled to $0.02 \mathrm{~Hz}$ and a low-pass with a frequency 0.4-fold the decimation frequency. Then, we compare the 2-year data with the velocity measurements at the ICEH and TAJH stations, for which the correlations between the velocity changes and 
the seismic intensities have already been discussed and that exhibit large amplitudes for the

383

384 secondary velocity drop (see Figure $2 b$ ). In the shallow part of the crust, the deep fluid upwelling is likely to be localized in the volcano feeding zones. Under these conditions, the relative positions of the tiltmeters with respect to fluid upwelling determine the polarity of the recordings. This is the reason why the results are present with arbitrary polarities, to highlight the identifiable corresponding observations between the seismic velocities and the ground tilt.

After gap filling, the tiltmeter raw data are low-pass filtered to focus on the daily changes in the ground tilt. The comparisons between velocity and tilt changes are shown in Figure 4. Except for Figures 4a and d, the tilt recordings are plotted upside-down. The data in the other Figures are represented conventionally. The time series of the changes in the seismic velocities and ground tilt show striking common features. Both the long-term trends and the short-term transient changes are almost identical to each other over the 2-year postseismic period. The tilt recordings from the E-W components change by $\sim \mu$ rad at both stations, and during the second drop period, the N-S component changes by $\sim-3 \mu \mathrm{rad}$ at TAJH and $\sim 0.5$ $\mu \mathrm{rad}$ at ICEH.

These simultaneous changes in the seismic velocity and the ground tilt indicate that the ground tilt is useful to confirm subtle local changes in seismic velocities. However, due to the instability of the tiltmeter data at the different locations, and due to the very local nature of the measures, a few sites show such similar functional correlations, but not all of them. There are no systematic changes with the same anomaly for all stations. Nevertheless, it is worth emphasizing that this is the first observation of a strong correlation between seismic velocity changes and ground tilt. We also check the GPS time series of the displacements. No 
equivalent changes to the tilt highlight this velocity change anomaly. Our conclusion is consistent with the discussion by Lesparre et al. (2017) that tiltmeter has higher resolutions on detecting the small-scale deformation and internal motion than the geodetic methods such as GPS, which works when the stain is sufficiently big in large scale.

412 Based on the parallel evolution in seismic velocity and tilt, we can conclude that both the local tilt and the velocity changes share the same physical origin. This deformation might be in the volcanic system, as station ICEH is close to the central volcanic chains. The deformation might also be due to fluid transport in the crust, as observed with the migration of seismicity studied by Yoshida et al. (2019), or with the fluid upwelling through fractured rock zones (Aso et al., 2013).

\section{Further seismological evidence}

420

421 We show that the cause of the anomalous velocity drop is also distinguishable in local ground

422 tilt records for some stations. At the same time, there is also a significant increase in LFEs in the volcanic area in Honshu. The spread distribution of both the LFEs and the velocity anomaly in Honshu might relate to fluid migration after the Tohoku-Oki earthquake. In this section, we recall the depth-dependent seismic velocity changes by Wang et al. in 2019 and discuss some further seismological evidence of changes in the fault strength from an earthquake swarm in Honshu and the fluid-driven swarms that widely exist in Honshu.

429 Yoshida et al. $(2016,2017,2019)$ report on temporal variations of fault strength calculated using an earthquake swarm in central Honshu. The change in fault strength results from fluid migration starting after the Tohoku-Oki earthquake. Hypocenters in the earthquake sequence 
exhibit a distinct migration behavior analogous to the fluid-injection induced seismicity,

433

434

435

436

437

438

439

440

441

442

444

445

446

447

448

449

450

451 Tohoku-Oki earthquake. They concluded that there is migration of the hypocenters of

which supports this hypothesis. All of these studies prove that in the volcanic area, large earthquakes trigger many seismic clusters and pore pressure changes with time, due to the fluid migration. These changes have continuity and directivity of both their temporal and spatial distributions.

We refer now to the time series of fault strength data in Figure 13 of Yoshida et al. (2016). There is an immediate drop in the fault strength following the mainshock. As time goes by after the Tohoku-Oki earthquake, the strength tends to recover gradually, while there is an anomalous drop of $\sim 10 \%$ that started from around 350 days after the earthquake in early 2012 . This drop of fault strength is synchronous to the simultaneous seismic velocity anomaly. We discuss in detail in the Appendix the relationship between the fault strength and the seismic velocity changes in the same region, the southern limitation of velocity anomaly, where there is also the concentration of LFEs. Due to the sensitivity of tilt to changes in fluid and the simultaneous drop in fault strength, we infer that the main cause of this second drop anomaly is an increase in pore pressure.

As well as their observations of the local earthquake swarms, Okada et al. (2015) studied some widely distributed regional earthquakes along the volcanic axis in Honshu after the earthquake swarms driven by changes in crustal fluid distribution and permeability. Kosuga (2014) report on the spatiotemporal migration of seismic activity near the Moriyoshi-zan volcano in north-eastern Japan, with the implication of geofluid migration and a mid-crustal fluid reservoir. When the Tohoku-oki earthquake occurred, there was rapid regional 
extension of the crust. Such extension of the crust and changes in crustal permeability led to a

457 loss of equilibrium of the fluid system.

458 In a previous paper (Wang et al., 2019), we have investigated depth-dependent time series of 459 seismic velocity changes after the Tohoku-oki earthquake (Figure 8 of Wang et al., 2019),

460 We found indications of a delayed velocity drop propagating from the deep part up to the 461 shallow part and we have suggested a possible upward fluid flow, which may control the decreases in seismic velocity. Based on the inverted velocity changes at depth, we speculate that the arrival of upward fluid in the shallow crust from the mantle is responsible for the secondary velocity decreases in early 2012 widely spread over the volcanic chain. Assuming a diffusion process, to relate the distance from the source of the fluids and the time required for the diffusion front to propagate, we rely on Equation (4) (e.g., Shapiro et al., 1997):

$$
r=\sqrt{4 \pi D t}
$$

where $r$ is the distance from the source of the fluids, $t$ is the time required for the diffusion 471 front to propagate, and D is the diffusivity of the pore pressure. Considering a distance of 20 $\mathrm{km}$ from the lower crust, where the depth represents a reservoir of high-pressure for fluids released up to the surface, the duration of fluid propagation is around 11 months, the 474 corresponding average diffusivity is of the order of $1 \mathrm{~m}^{2} / \mathrm{s}$. This value is in the range of the calculated diffusivity $0.4-1.5 \mathrm{~m}^{2} / \mathrm{s}$ by Kitagawa et al. (2007) near the Nojima fault zone in Japan after the $\mathrm{M}_{\mathrm{w}} 7.2,1995$ Kobe earthquake.

477

478 Based on the consistency between the reduction in the fault strength and the velocity decrease, 479 we can conclude that increase in pore pressure produced by up-moving fluid is responsible 480 for the drops in velocity in 2012. Thus, there appears to be an increase in seismic events 
during this period. However, this lacks direct correlation between dynamic stress from earthquakes and the velocity changes. The decrease in the velocity and the temporary increase in the seismic events are both the results of changes in pore pressure due to fluid motion.

\section{Discussion and conclusion}

Here, we have focused on the anomaly of very localized seismic wave velocity changes near the central volcanic chain of Honshu Island in Japan. This anomaly occurs about 11 months after the 2011 Tohoku-Oki Earthquake. We observe a seismic velocity anomaly that is comparable to that associated with the inland $\mathrm{M}_{\mathrm{w}} 6.8$ Iwate-Miyagi Nairiku shallow earthquake in 2008. However, there is a lack of direct explanation as coseismic change from any significant earthquake occurrence. Moreover, this velocity decrease is not instantaneous, but shows a continuous slowdown over several months.

To explain this anomaly, we analyze the changes in the surrounding environmental and use two linear models to correct possible changes in seismic velocity based on the local meteorological and oceanographic recordings. The remained velocity decrease helps excluding the anomaly from being an effect of environment-induced changes. Further study

500 on the earthquake moment intensity takes into account the geometric and inherent attenuation.

501 We find that the changes in the moment intensity and seismic wave velocity before the

502 Tohoku-Oki earthquake show an excellent linear correlation. However, there is an absence of vigorous moment intensity during the anomaly to directly explain the velocity decrease

504 anomaly. By comparison with LFE activity, the consistency of the temporal and spatial 505 distributions suggests shared physical origins of concentration of the LFEs and the velocity 
506 drop. Further observations of the ground tilt from the co-sited Hi-net tiltmeters confirm the

507 independently measurable physical changes in the crust that are responsible for the velocity

508 anomaly. As the ground tilt is under the influence of local changes, through this comparison

509 and the above analysis, we believe that the localized velocity decrease observed is related to

510 fluid activities in the volcanoes, or their fault systems, where the presence of a crack makes

511 the flow of deep fluids easier. Additionally, we show a small scale decrease in fault strength

512 driven by the earthquake swarms related to the fluid activities. By considering a simple fluid

513 diffusion process, we obtain a diffusion coefficient in the order of $1 \mathrm{~m}^{2} / \mathrm{s}$. This assumes fluid

514 migrating through the crust following the crustal extension induced by the Tohoku-Oki

515 earthquake. The fluid migration generates not only increases in fluid-driven swarm seismicity

516 and LFEs in Honshu, but also pore pressure, and hence decreases in seismic wave velocities

517 in the same regions. 


\section{Acknowledgements}

519 The authors want to thank Mariano Supino for the contribution on LFEs catalog,Hisashi

520 Nakahara, Takeshi Nishimura, Kiwamu Nishida, Yosuke Aoki, and Kaoru Sawazaki for

521 fruitful discussions. Q.-Y. Wang specially thanks William Frank for the support on finishing

522 this paper. This work was supported by the European Research Council (ERC) under the

523 European Union Horizon 2020 Research and Innovation Program (Grant Agreement 742335,

524 F-IMAGE). Most of the computations presented in this paper were performed using the

525 GRICAD infrastructure (https://gricad.univ-grenoble-alpes.fr), which is supported by

526 Grenoble research communities.

527

\section{Data availability}

529 The Hi-net seismic and tilt data used here are available from the National Research Institute

530 for Earth Science and Disaster Prevention (NIED, http://www.hinet.bosai.go.jp). 
531 Appendix

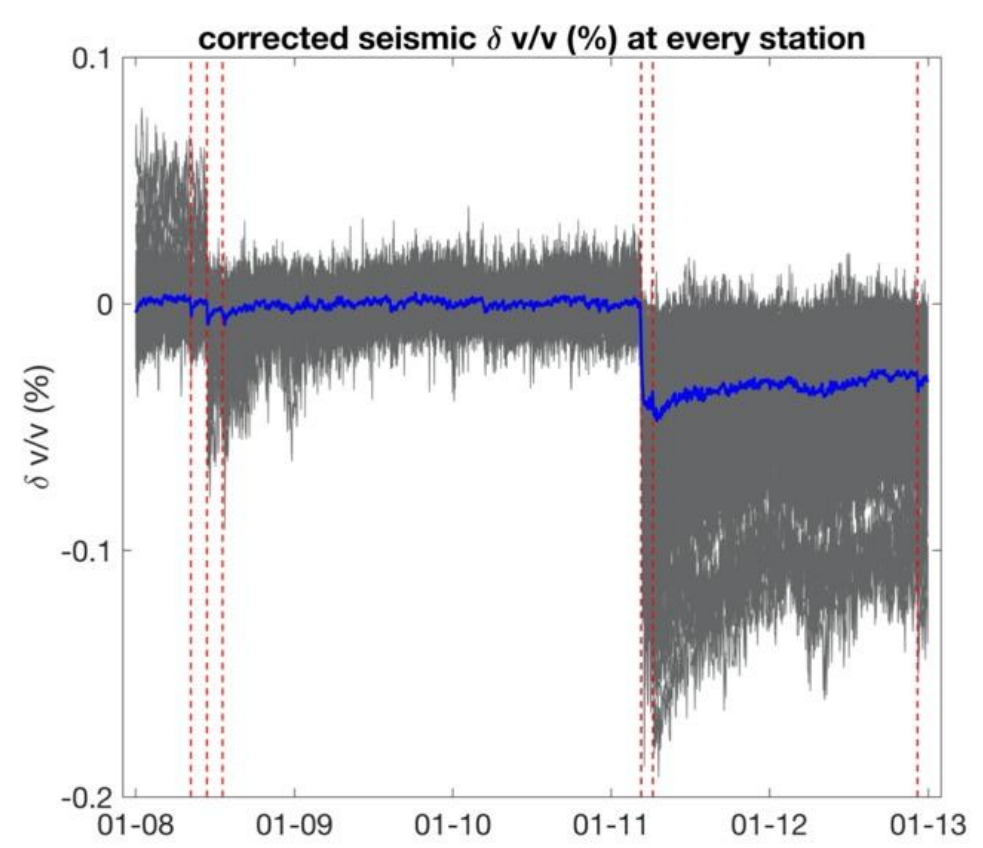

532

533 Figure A1. Corrected seismic velocity changes from 236 Hi-net stations in Figure 1a. The blue curve is the

534 averaged time series over the 236 stations. The red vertical dashed lines indicate the six earthquakes indicated in 535 Figure 1a.

536

537 


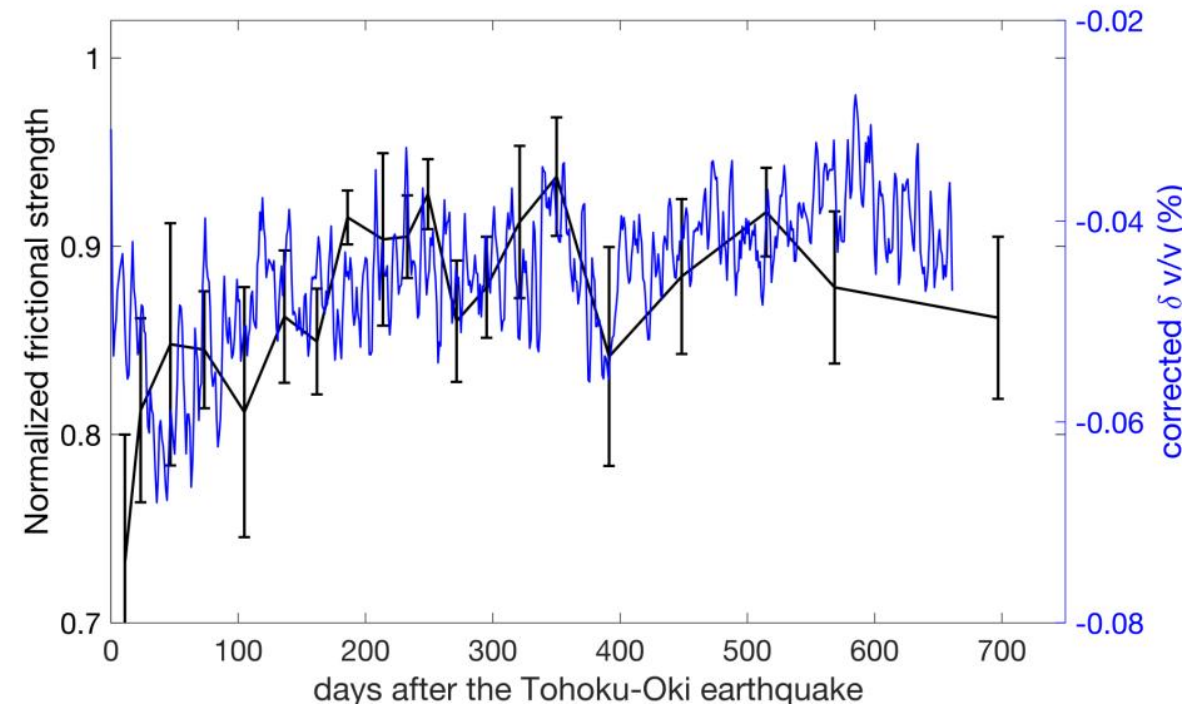

539 Figure A2. Comparison of the fault strength (error bars calculated by Yoshida et al. (2016) using earthquake 540 swarms around Hi-net station ATKH) at a volcanic site and the seismic velocity changes at station ATKH.

541 Black curve, calculated fault strength with error bars; blue curve, 5-day moving average smoothed seismic 542 velocity changes after removing environmental effects; red shaded area, anomalous period $\sim 350$ days after the

543 Tohoku-Oki earthquake in early 2012.

544

545 We refer to the changes in fault strength calculated by Yoshida et al. (2016) in a volcanic 546 area using the earthquake swarms from the day of the Tohoku-Oki earthquake until 700 days 547 after the earthquake. As the time increases, there are fewer seismic events. Hence, the 548 interval of the binned plot gets larger, and the accuracy can also decrease. Nevertheless, there 549 is a clear drop in the fault strength from day 350 after the mainshock (Figure A2). This 550 decrease happens at the same time as the secondary velocity drop distributed in the volcanic areas.

552

553 Then we compare the strength time series with the seismic velocity changes after correcting 554 for the possible environmental perturbation-related changes at the ATKH Hi-net station. This 555 station is located in the center of the earthquake swarm. Figure A2 shows the fault strength 556 and the residuals of the seismic velocity changes after the changes related to external forcing 
557 have been removed. There is an apparent decrease of $\sim 0.015 \%$ in the seismic velocity for the 558 days around 300 to 400 . In this same time period, there is an $\sim 10 \%$ decrease in the 559 normalized fault strength. This simultaneous change indicates that the velocity drop and the 560 strength drop are due to the same physical process. This process involves an increase in the 561 pore pressure associated with the upwelling flow of deep fluid that was triggered by the 562 Tohoku-oki earthquake and reached the shallow crust about 11 months later. 


\section{References}

564

565

Aki, K., Fehler, M., Das, S. 1977. Source mechanism of volcanic tremor: fluid-driven crack models and their application to the 1963 Kilauea eruption. Journal of Volcanology and Geothermal Research. 2, 259-287. https://doi.org/10.1016/0377-0273(77)90003-8

568

Aso, N., Ohta, K., Ide, S. 2013. Tectonic, volcanic, and semi-volcanic deep low-frequency

569 earthquakes in western Japan. Tectonophysics. 600, 27-40.

570 https://doi.org/10.1016/j.tecto.2012.12.015

\section{1}

Brenguier, F., Campillo, M., Hadziioannou, C., Shapiro, N.M., Nadeau, R.M., Larose, E. 2008. Postseismic relaxation along the San Andreas fault at Parkfield from continuous seismological observations. Science. 321(5895), 1478-1481.

575 https://doi.org/10.1126/science.1160943

576

Brenguier, F., Campillo, M., Takeda, T., Aoki, Y., Shapiro, N.M., Briand, X., et al. 2014. Mapping pressurized volcanic fluids from induced crustal seismic velocity drops. Science. 345(6192), 80-82. https://doi.org/10.1126/science.1254073

Chen, J.H., Froment, B., Liu, Q.Y., Campillo, M. 2010. Distribution of seismic wave speed

\section{1} changes associated with the 12 May $2008 \mathrm{M}_{\mathrm{w}}$ 7.9 Wenchuan earthquake. Geophys. Res. Lett., 37, L18302, https://doi.org/10.1029/2010GL044582

Chouet, B., Koyanagi, R.Y., Aki, K. 1987. Origin of volcanic tremor in Hawaii. Part II. Theory and discussion. US Geological Survey Professional Paper. Chapter 45, 1259-

Donaldson, C., Winder, T., Caudron, C., White, R.S. 2019. Crustal seismic velocity responds to a magmatic intrusion and seasonal loading in Iceland's Northern Volcanic Zone. 
588

589

590

591

592

593

594

595

596

597

598

599

600

601

602

603

604

605

606

607

608

609

610

Dzurisin, D. 2003. A comprehensive approach to monitoring volcano deformation as a window on the eruption cycle. Reviews of Geophysics. 41, 1001. https://doi.org/10.1029/2001RG000107

Froment, B., Campillo, M., Chen, J.H., Liu, Q.Y. 2013. Deformation at depth associated with the 12 May $2008 \mathrm{M}_{\mathrm{w}}$ 7.9 Wenchuan earthquake from seismic ambient noise monitoring. Geophys. Res. Lett. 40, 78-82. https://doi.org/10.1029/2012GL053995

Hanks, T.C., Kanamori, H. 1979. A moment magnitude scale. J. Geophys. Res., 84(B5), 2348-2350, htts://doi.org/10.1029/JB084iB05p02348.

Hasegawa, A., Yamamoto, A. 1994. Deep, low-frequency microearthquakes in or around seismic low-velocity zones beneath active volcanoes in northeastern Japan. Tectonophysics. 233(3-4), 233-252. https://doi.org/10.1016/0040-1951(94)90243-7

Hillers, G., Campillo, M., Ma, K.F. 2014. Seismic velocity variations at TCDP are controlled by MJO driven precipitation pattern and high fluid discharge properties. Earth Planet. Sci. Lett. 391, 121-127. https://doi.org/10.1016/j.eps1.2014.01.040

Hillers, G., Ben-Zion, Y., Campillo, M., Zigone, D. 2015. Seasonal variations of seismic velocities in the San Jacinto fault area observed with ambient seismic noise. Geophys. J. Int. 202(2), 920-932. https://doi.org/10.1093/gji/ggv151

Hobiger, M., Wegler, U., Shiomi, K., Nakahara, H. 2012. Coseismic and postseismic elastic wave velocity variations caused by the 2008 Iwate-Miyagi Nairiku earthquake, Japan. J. Geophys. Res. 117, B09313. https://doi.org/10.1029/2012JB009402

Katsumata, A. 1996. Comparison of magnitudes estimated by the Japan meteorological agency with moment magnitudes for intermediate and deep earthquakes. Bulletin of the Seismological Society of America. 86 (3): 832-842. 
611 Katsumata, A., Kamaya, N. 2003. Low-frequency continuous tremor around the Moho 612 discontinuity away from volcanoes in the southwest Japan. Geophys. Res. Lett. 30(1), 613 1020. https://doi.org/10.1029/2002gl015981

614 Kitagawa, Y., Fujimori, K., \& Koizumi, N. 2007. Temporal change in permeability of the $615 \quad$ Nojima fault zone by repeated water injection experiments. Tectonophysics. 443, 183$616 \quad$ 192. https://doi.org/10.1016/j.tecto.2007.01.012

617 Kosuga, M. 2014. Seismic activity near the Moriyoshi-zan volcano in Akita Prefecture, 618 northeastern Japan: implications for geofluid migration and a midcrustal geofluid 619 reservoir Geofluid processes in subduction zones and mantle dynamics. Earth Planet Sp. $620 \quad 66,77$. https://doi.org/10.1186/1880-5981-66-77

621 Lesparre, N., Boudin, F., Champollion, C., Chéry, J., Danquigny, C., Seat, H. C., et al. (2017). 622 New insights on fractures deformation from tiltmeter data measured inside the Fontaine 625 626 https://doi.org/10.1046/j.1365-246X.2003.01991.x

Nakamichi, H., Ukawa, M., Sakai, S. 2004. Precise hypocenter locations of midcrustal low633 frequency earthquakes beneath Mt. Fuji, Japan. Earth Planet Sp. 56, e37-e40. https://doi.org/10.1186/bf03352542 
635 Obara, K., Kasahara, K., Hori, S., Okada, Y. 2005. A densely distributed high-sensitivity 636 seismograph network in Japan: Hi-net by National Research Institute for Earth Science 637 and Disaster Prevention. Review of Scientific Instruments. 76.

$638 \quad$ https://doi.org/10.1063/1.1854197

639 Obermann, A., Froment, B., Campillo, M., Larose, E., Planès, T., Valette, B., et al. 2014. 640 Seismic noise correlations to image structural and mechanical changes associated with the $M_{w}$ 7.9 2008 Wenchuan earthquake. J. Geophys. Res.: Solid Earth, 119(4), 31553168. https://doi.org/10.1002/2013JB010932

Okada, T., Matsuzawa, T., Umino, N., Yoshida, K., Hasegawa, A., Takahashi, H., et al. 2015. Hypocenter migration and crustal seismic velocity distribution observed for the inland earthquake swarms induced by the 2011 Tohoku-Oki earthquake in NE Japan:

647 implications for crustal fluid distribution and crustal permeability. Geofluids. 15, 293309. https://doi.org/10.1111/gfl.12112

648

Okada, Y., Kasahara, K., Hori, S., Obara, K., Sekiguchi, S., Fujiwara, H., Yamamoto, A. 2004. Recent progress of seismic observation networks in Japan - Hi-net, F-net, K-net and KiK-net. Earth Planet Sp. 56, xv-xxviii. https://doi.org/10.1186/BF03353076

Peng, Z., Ben-Zion, Y. 2006. Temporal changes of shallow seismic velocity around the 652 Karadere-Düzce branch of the north Anatolian fault and strong ground motion. Pure appl. geophys. 163, 567-600. https://doi.org/10.1007/s00024-005-0034-6

654 Poli, P., Marguin, V., Wang, Q.-Y., D’Agostino, N., Johnson, P. 2020. Seasonal and 655 coseismic velocity variation in the Region of L'Aquila from single station measurements and implications for crustal rheology. Journal of Geophysical Research: Solid Earth.

657 125(7). https://doi.org/10.1029/2019jb019316 
658 Poupinet, G., Ellsworth, W.L., Frechet, J. 1984. Monitoring velocity variations in the crust 659 using earthquake doublets: an application to the Calaveras Fault, California. J. Geophys. 660 Res. 89(B7), 5719. https://doi.org/10.1029/JB089iB07p05719

661 Richter, T., Sens-Schönfelder, C., Kind, R., Asch, G. 2014. Comprehensive observation and 662 modeling of earthquake and temperature-related seismic velocity changes in northern Chile with passive image interferometry. Journal of Geophysical Research: Solid Earth. 119, 4747-4765, https://doi.org/10.1002/2013JB010695

665

Sato, H., Takahashi, H., Yamamoto, E., Fukuo, N., Uehara, M., Terasawa, Y. 1980.

666

667 Development of the crustal tilt observation method using borehole-type tiltmeters. J. Seismol. Soc. Japan. 33(3), 343-368. https://doi.org/10.4294/zisin1948.33.3_343

Sawazaki, K., Kimura, H., Shiomi, K., Uchida, N., Takagi, R., Snieder, R. 2015. Depth669 dependence of seismic velocity change associated with the 2011 Tohoku earthquake,

670

671

672

673

Schaff, D.P., Beroza, G.C. 2004. Coseismic and postseismic velocity changes measured by

674 repeating earthquakes. J. Geophys. Res. 109, B10302.

675 https://doi.org/10.1029/2004JB003011

676

677

678

Sens-Schönfelder, C., Wegler, U. 2006. Passive image interferemetry and seasonal variations

Sens-Schönfelder, C., Wegler, U. 2011. Passive image interferometry for monitoring crustal 680 changes with ambient seismic noise. Comptes Rendus Geoscience. 343(8-9), 639-651.

681 https://doi.org/10.1016/j.crte.2011.02.005 
Shapiro, N.M., Campillo, M., Kaminski, E., Vilotte, J.P., Jaupart, C. 2018. Low-frequency earthquakes and pore pressure transients in subduction zones. Geophys. Res. Lett. 45, 11,083-11,094. https://doi.org/10.1029/2018GL079893

Shapiro, S.A., Huenges, E., Borm, G. 1997. Estimating the crust permeability from fluidinjection-induced seismic emission at the KTB site. Geophysical Journal International. 131, F15-F18. https://doi.org/10.1111/j.1365-246X.1997.tb01215.x

Taira, T., Brenguier, F., Kong, Q. 2015. Ambient noise-based monitoring of seismic velocity changes associated with the 2014 Mw 6.0 South Napa earthquake. Geophys. Res. Lett. 42(17), 6997-7004. https://doi.org/10.1002/2015GL065308

Takada, Y., Fukushima, Y. 2013. Volcanic subsidence triggered by the 2011 Tohoku earthquake in Japan. Nature Geoscience. 6, 637-641. https://doi.org/10.1038/ngeo1857

Tokuda, T., Shimada, H. 2019. Classes of low-frequency earthquakes based on inter-time distribution reveal a precursor event for the 2011 great Tohoku Earthquake. Sci Rep. 9, 9330. https://doi.org/10.1038/s41598-019-45765-0

Tsuji, T., Kawamura, K., Kanamatsu, T., Kasaya, T., Fujikura, K., Ito, Y., et al. 2013. Extension of continental crust by anelastic deformation during the 2011 Tohoku-oki earthquake: the role of extensional faulting in the generation of a great tsunami. Earth Planet. Sci. Lett. 364, 44-58. https://doi.org/10.1016/j.eps1.2012.12.038

Uchide, T., Imanishi, K. 2018. Underestimation of microearthquake size by the magnitude scale of the Japan Meteorological Agency: influence on earthquake statistics. J. Geophys. Res.: Solid Earth. 123, 606-620. https://doi.org/10.1002/2017JB014697

Ueda, H., Fujita, E., Ukawa, M., Yamamoto, E., Irwan, M., Kimata, F. 2005. Magma intrusion and discharge process at the initial stage of the 2000 activity of Miyakejima, central Japan, inferred from tilt and GPS data. Geophys. J. Int. 161, 891-906. https://doi.org/10.1111/j.1365-246X.2005.02602.x 
707

708

709

710

711

712

713

714

715

716

717

718

719

720

721

722

723

724

725

726

727

728

729

730

731

Wang, Q.-Y., Brenguier, F., Campillo, M., Lecointre, A., Takeda, T., Aoki, Y. 2017. Seasonal crustal seismic velocity changes throughout Japan. J. Geophys. Res.: Solid Earth. 122, 7987-8002. https://doi.org/10.1002/2017JB014307

Wang, Q.-Y., Campillo, M., Brenguier, F., Lecointre, A., Takeda, T., Hashima, A. 2019. Evidence of changes of seismic properties in the entire crust beneath Japan after the $M_{w}$ 9.0, 2011 Tohoku-oki earthquake. J. Geophys. Res.: Solid Earth. 124, 8924-8941. https://doi.org/10.1029/2019JB017803

Wegler, U., Nakahara, H., Sens-Schönfelder, C., Korn, M., Shiomi, K. 2009. Sudden drop of seismic velocity after the $2004 \mathrm{M}_{\mathrm{w}} 6.6$ mid-Niigata earthquake, Japan, observed with passive image interferometry. J. Geophys. Res. 114(B6), B06305. https://doi.org/10.1029/2008JB005869

Yoshida, K., Hasegawa, A., Yoshida, T. 2016. Temporal variation of frictional strength in an earthquake swarm in NE Japan caused by fluid migration. J. Geophys. Res.: Solid Earth. 121, 5953-5965. https://doi.org/10.1002/2016JB013022

Yoshida, K., Hasegawa, A., Yoshida, T., Matsuzawa, T. 2019. Heterogeneities in stress and strength in Tohoku and its relationship with earthquake sequences triggered by the 2011 M9 Tohoku-Oki earthquake. Pure Appl. Geophys. 176, 1335-1355. https://doi.org/10.1007/s00024-018-2073-9

Yoshida, K., Saito, T., Urata, Y., Asano, Y., Hasegawa, A. 2017. Temporal changes in stress drop, frictional strength, and earthquake size distribution in the 2011 YamagataFukushima, NE Japan, earthquake swarm, caused by fluid migration. J. Geophys. Res.: Solid Earth. 122, 10,379-10,397. https://doi.org/10.1002/2017JB014334

Yu, Z., Zhao, D., Niu, X., Li, J. 2018. Spatiotemporal distribution of low-frequency earthquakes in southwest Japan: evidence for fluid migration and magmatic activity. J. Asian Earth Sci. 151, 148-172. https://doi.org/10.1016/j.jseaes.2017.10.033 